\title{
Peritoneal gliomatosis: a case report
}

\author{
Enrique Vaca ${ }^{1}$, Claudia V. Ventura ${ }^{2}$, Jefferson Nieves ${ }^{3 *}$, Camilo Acuña ${ }^{3}$, Daniel A. Rivera ${ }^{3}$
}

Department of ${ }^{1}$ Oncology Surgery, ${ }^{2}$ Patology, ${ }^{3}$ General Surgery, Hospital Regional de Alta Especialidad del Bajío. León, Guanajuato, México

Received: 07 July 2021

Accepted: 16 August 2021

\section{*Correspondence:}

Dr. Jefferson Nieves,

E-mail: jeffnc.md@gmail.com

Copyright: $\odot$ the author(s), publisher and licensee Medip Academy. This is an open-access article distributed under the terms of the Creative Commons Attribution Non-Commercial License, which permits unrestricted non-commercial use, distribution, and reproduction in any medium, provided the original work is properly cited.

\begin{abstract}
Peritoneal gliomatosis is the mature neuroglial tissue in peritoneum, this is commonly associated with immature teratoma. Can be associated with ascites alone or ascites and pleural effusion in which case it is called pseudo Meigs syndrome, the lymph node invasion has been described. In the imaging studies such computed tomography they can be show as multiple peritoneal nodules, the positron emission tomography has shown utility in cases of doubt of recurrence of mature teratoma without evidence of primary tumor with elevated tumor marker. The initial treatment depends on the treatment of the teratoma, reserving the surgical treatment of the peritoneal gliomatosis in the presence of complications related to the implants. A 21-year-old woman without chronic degenerative disease story with clinical presentation of abdominal distension, a CT scan is performed that shows a right ovary tumor; a laparotomy was performed in which ascites and peritoneal nodules were evidenced suggesting the presence of carcinomatosis. Histopathological study demonstrated peritoneal gliomatosis.
\end{abstract}

Keywords: Peritoneal gliomatosis, Gliomatosis peritonei, Immature teratoma, Ovarian cancer

\section{INTRODUCTION}

Peritoneal gliomatosis (GP) is the mature neuroglial tissue that infiltrates the peritoneal tissue and is commonly associated with immature teratoma. It is a rare entity first reported in 1905, being described approximately 100 cases to date. The pathogenesis is poorly understood and there is currently controversy regarding it, being attributed to dissemination after teratoma rupture. Symptoms at diagnosis are variable, with multiple associations described without specific symptoms or signs. Associations with ascites, pleural effusion and endometriosis have been described. Imaging studies such computed tomography (CT) can detect peritoneal nodules but lack specificity. Differential diagnosis should be made with carcinomatosis, peritoneal tuberculosis, and other granulomatous disease, therefore it requires histopathological diagnosis. There are several series of cases that describe the clinical behavior and results before surgical treatment and the expectant attitude according to the stage of the primary tumor.

\section{CASE REPORT}

A 21-year-old woman without chronic degenerative disease story, she had 3 pregnancies, 1 cesarean sections, and 2 unintended abortions, use of injectable hormonal contraceptives, occasional alcohol consumption, without drug addictions. The patient had clinical presentation around of 2 months with a progressive increase in the abdominal perimeter, a CT scan is performed that shows a right ovary tumor, heterogeneous, with uptake of contrast medium, ascitis and presence of multiple peritoneal nodules, an ovarian tumor protocol surgery was planned. The results of the pre-surgical examinations are shown in Table 1.

An exploratory laparotomy was performed with evacuation of $4000 \mathrm{ml}$ of ascites fluid, a dependent tumor 
of the right ovary was evidenced, with a solid-cystic component of approximately $20 \mathrm{~cm}$ in diameter without evidence of rupture of the capsule, peritoneal carcinomatosis was documented with implants of approximately $5 \mathrm{~mm}$ in the anterior peritoneum, parietocolic gutter, splenic surface, pelvic hollow and cul-de-sac, calculating a peritoneal carcinomatosis index of 10. The tumor dependent on the right annex was resected and omentectomy plus take of peritoneum sample was done, an ascites fluid sample was taken for cytology. The histopathology study demonstrated the presence of mature glial cells infiltrating the peritoneal tissue (Figure 1) (Table 2).

Table 1: Lab test results.

\begin{tabular}{|c|c|}
\hline \multicolumn{2}{|l|}{ Admission labs } \\
\hline Creatinine (mg/dL) & 0.5 (NV 0.52-1.04) \\
\hline Urea (mg/dL) & 27 (NV 15.0-36.0) \\
\hline Erythrocytes $(\mathbf{u} / \mathbf{L})$ & $4.9 \times 10^{6}(\mathrm{NV} 4.10-5.10)$ \\
\hline Hemoglobin (g/dL) & $13.4(\mathrm{NV} 12.3-15.3)$ \\
\hline Hematocrit (\%) & $39.2(\mathrm{NV} \mathrm{36-45)}$ \\
\hline $\begin{array}{l}\text { Medium corpuscular } \\
\text { volume }(\mathbf{M C V})(\mathbf{f L})\end{array}$ & 80.0 (NV 80.0-100.0) \\
\hline $\begin{array}{l}\text { Average hemoglobin } \\
\text { concentration (AHC) (pg) }\end{array}$ & 27.3 (NV 26.3-33.8) \\
\hline Leukocytes (u/L) & $\begin{array}{l}9.38 \times 10^{3}(\mathrm{NV} 4.40- \\
11.30)\end{array}$ \\
\hline Neutrophils (\%) & 74 \\
\hline Lymphocytes (\%) & 19 \\
\hline Monocytes (\%) & 6 \\
\hline Basophils (\%) & 0 \\
\hline Platelets (uL) & $311 \times 10^{3}$ \\
\hline Total protein $(\mathrm{gm} / \mathrm{dL})$ & 7.7 \\
\hline Albumin (gm/dL) & $4.0(\mathrm{NV} 3.5-5.0)$ \\
\hline Total bilirrubin (mg/dL) & $0.4(\mathrm{NV} 0.2-1.3)$ \\
\hline Direct bilirubin (mg/dL) & $0.1(\mathrm{NV} 0.3)$ \\
\hline Alkaline phosphatase (U/L) & 107 (NV 36-126) \\
\hline TGO $(\mathbf{U} / \mathbf{L})$ & 19 (NV 17-59) \\
\hline TGP (U/L) & 27 (NV 21-72) \\
\hline $\begin{array}{l}\text { Prothrombin time (PT) } \\
\text { (Sec) }\end{array}$ & 14 (NV 9.8-12.8) \\
\hline INR & $1.05(\mathrm{NV} \mathrm{1.5-2.5)}$ \\
\hline $\begin{array}{l}\text { Patial thromboplastin time } \\
\text { (PTT) }\end{array}$ & 28.5 (NV 22.5-33.5) \\
\hline Carcinoembryonic antigen & 9.6 \\
\hline Ca 125 & 297 \\
\hline Beta-HCG & $<0.50$ \\
\hline
\end{tabular}

Table 2: Histological diagnosis of samples.

\begin{tabular}{|ll|}
\hline Histopathological report of samples \\
\hline Ovarian tumor & $\begin{array}{l}\text { Mature teratoma with } \\
\text { components of all three } \\
\text { layers }\end{array}$ \\
\hline $\begin{array}{l}\text { Greater omentum and } \\
\text { peritoneum sample }\end{array}$ & Peritoneal gliomatosis \\
\hline Ascites fluid sample & $\begin{array}{l}\text { Chronic inflammatory } \\
\text { changes }\end{array}$ \\
\hline
\end{tabular}

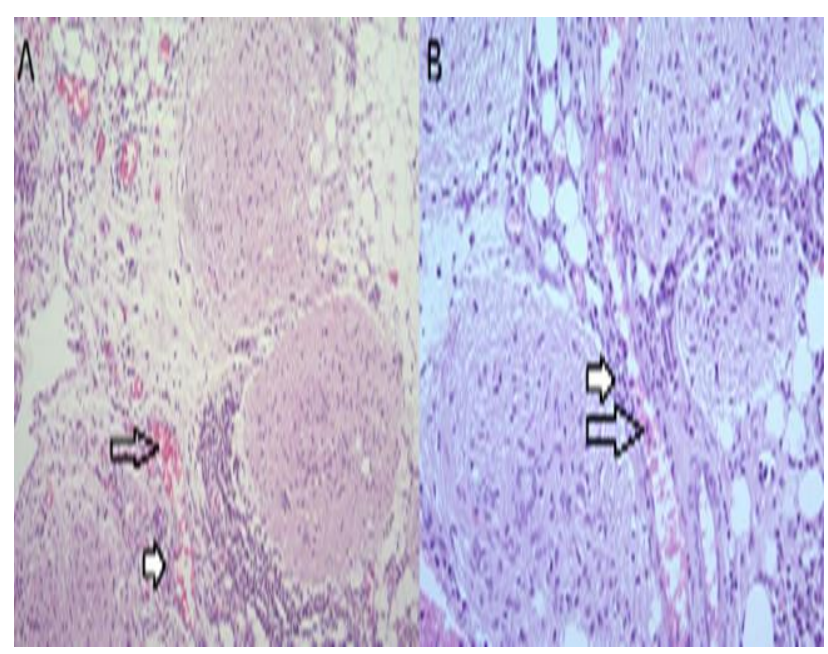

Figure 1: Hematoxylin and eosin staining (A: 10X, B: 40X). Miliary implantation of a peritoneum sample showing infiltration of mature glial tissue (solid arrow) and inflammatory infiltrate with a predominance of lymphocytes (hollow arrow).

After surgical treatment, he evolved favorably and was discharged 24 hours after surgery. It did not require systemic treatment; She has surveillance without data of recurrence at one year of follow-up.

\section{DISCUSSION}

GP is the peritoneal implantation of mature glial tissue usually related to mature and immature ovarian teratoma; reported for the first time in 1905, it is rare, with about 100 cases reported in the English literature.

Cases associated with bilateral ovarian teratomas have been described, Karlo et al described the association of GP with hepatic teratoma in a 59-year-old patient. $^{1}$ Ascites may be present as well as pleural effusion constituting a pseudo Meigs syndrome. ${ }^{3}$ The spread of GP to lymph nodes has been documented as well as the coexistence with endometriosis. ${ }^{4}$

In the CT are observed as multiple peritoneal nodules of variable size or omental cake. During surgery, the macroscopic appearance is similarly to carcinomatosis, peritoneal tuberculosis, endometriosis, ectopic decidua, peritoneal leiomyomatosis. ${ }^{5}$ In the absence of primary recurrence in CT with elevated tumor marker, positron emission tomography can help identify areas with GPrelated metabolic activity. ${ }^{6}$

The pathogenesis has classically been described as dissemination after teratoma rupture or angiolymphatic dissemination, however it has been questioned due to the description of GP genetically different from that of the ovarian tumor, which suggests that it derives from cells Mullerian pluripotent stem. 
The immature teratoma can be associated with two forms of peritoneal spread, GP and teratoma growth syndrome. Treatment depends on the characteristics of the teratoma, frequently receive adjuvant chemotherapy. ${ }^{3}$ Surgical management is complete resection for to avoid complications such as obstruction. There are several options such as peritonectomy, appendectomy, omentectomy and lymphadenectomy, depending on the macroscopic state during surgery. ${ }^{7}$

Bentivegna et al, analyzed the outcome of 10 patients who presented GP alone, with a mean follow-up of 39 months, there was no death associated with the disease and they remained totally asymptomatic for a long period, concluding that a conservative treatment without the need for surgery. ${ }^{8}$

In the present case presented with abdominal distension, ovarian tumor, ascites, and peritoneal nodules, which is consistent with the reported literature, initially carcinomatosis is suspected, however the diagnosis of GP was established by histology; conservative treatment and follow-up were chosen; without evidence of disease recurrence at one year of follow-up.

\section{CONCLUSION}

PG is a rare condition that is usually associated with immature teratoma and less frequently with mature teratoma; imaging studies are not specific enough for diagnosis, they manifest as peritoneal nodules, and their treatment depends in the first instance on the treatment of the teratoma and the presence of complications associated with the implants.

Funding: No funding sources Conflict of interest: None declared Ethical approval: Not required

\section{REFERENCES}

1. Wang J, Xu J, Zhang M, Li B. Gliomatosis peritonei with bilateral ovarian teratomas: A report of two cases. Oncol Lett. 2016;12(3):2078-80.

2. Benirschke $\mathrm{K}$, easterday $\mathrm{C}$, abramson D. Malignant solid teratoma of the ovary. Report of three cases. Obstet Gynecol. 1960;15:512-21

3. Lin C-S, Huang C, Li P-C, Hsu Y-H, Ding D-C. Huge ovarian mature cystic teratoma with gliomatosis peritonei and massive ascites in a postmenopausal woman. Tzu Chi Med J. 2019;31(4):289.

4. Kim NR, Lim S, Jeong J, Cho HY. Peritoneal and Nodal Gliomatosis with Endometriosis, Accompanied with Ovarian Immature Teratoma: A Case Study and Literature Review. Korean J Pathol. 2013;47(6):587.

5. Singh S, Agarwal R, Sehgal S, Verma S. Immature ovarian teratoma with peritoneal gliomatosis. Indian J Cancer. 2014;51(3):378.

6. Ohara T, Yamanoi K, Inayama Y, Ogura J, Sakai M, Suzuki H et al. Gliomatosis peritonei with $18 \mathrm{~F}$ fluorodeoxyglucose accumulation and contrast enhancement secondary to immature teratoma: A case report. Mol Clin Oncol. 2018;2

7. Wang D, Jia C, Feng R, Shi H, Sun J. Gliomatosis peritonei: a series of eight cases and review of the literature. J Ovarian Res. 2016;9(1):45.

8. Bentivegna E, Gonthier C, Uzan C, Genestie C, Duvillard P, Morice P et al. Gliomatosis Peritonei: A Particular Entity With Specific Outcomes Within the Growing Teratoma Syndrome. Int J Gynecol Cancer. 2015;25(2):244-9.

Cite this article as: Vaca E, Ventura CV, Nieves J, Acuña C, Rivera DA. Peritoneal gliomatosis: a case report. Int Surg J 2021;8:2789-91. 